\title{
Characteristics of size distributions at urban and rural locations in New York
}

\author{
M.-S. Bae ${ }^{1}$, J. J. Schwab ${ }^{1}$, O. Hogrefe ${ }^{1}$, B. P. Frank ${ }^{2}$, G. G. Lala ${ }^{1}$, and K. L. Demerjian ${ }^{1}$ \\ ${ }^{1}$ Atmospheric Sciences Research Center, University at Albany, State University of New York, Albany, New York, USA \\ ${ }^{2}$ Division of Air Resources, New York State Department of Environmental Conservation, Albany, NY, USA
}

Received: 4 September 2009 - Published in Atmos. Chem. Phys. Discuss.: 5 January 2010

Revised: 15 April 2010 - Accepted: 4 May 2010 - Published: 18 May 2010

\begin{abstract}
Paired nano- and long-tube Scanning Mobility Particle Sizer (SMPS) systems were operated for four different intensive field campaigns in New York State. Two of these campaigns were at Queens College in New York City, during the summer of 2001 and the winter of 2004. The other field campaigns were at rural sites in New York State.

The data with the computed diffusion loss corrections for the sampling lines and the SMPS instruments were examined and the combined SMPS data sets for each campaign were obtained. The diffusion corrections significantly affect total number concentrations, and in New York City, affect the mode structure of the size distributions. The relationship between merged and integrated SMPS total number concentrations with the diffusion loss corrections and the CPC number concentrations yield statistically significant increases (closer to 1) in the slope and correlation coefficient compared to the uncorrected values. The measurements are compared to $\mathrm{PM}_{2.5}$ mass concentrations and ion balance indications of aerosol acidity. Analysis of particle growth rate in comparison to other observations can classify the events and illustrate that urban and rural new particle formation and growth are the result of different causes. Periods of low observed $\mathrm{PM}_{2.5}$ mass, high number concentration, and low median diameter due to small fresh particles are associated with primary emissions for the urban sites; and with particle nucleation and growth for the rural sites. The observations of high $\mathrm{PM}_{2.5}$ mass, lower number concentrations, and higher median diameter are mainly due to an enhancement of photochemical reactions leading to condensation processes in relatively aged air. There are statistically different values for
\end{abstract}

Correspondence to: M.-S. Bae (minsbae@ hotmail.com) the condensation sink (CS) between urban and rural areas. While there is good association $\left(r^{2}>0.5\right)$ between the condensation sink (CS) in the range of $8.35-283.9 \mathrm{~nm}$ and $\mathrm{PM}_{2.5}$ mass in the urban areas, there is no discernable association in the rural areas. The average values computed for the CS lie in the range $8.7 \times 10^{-3}-3.5 \times 10^{-2} \mathrm{~s}^{-1}$.

\section{Introduction}

Atmospheric aerosols are ubiquitous in the Earth's atmosphere and affect our quality of life through many different processes (Hopke, 2009). As additional information comes to light concerning the role of nano particles in aerosol formation and growth, in manufacturing and nanotechnology, in human health effects, and in climate; the measurements of size distributions inclusive of particles in ultrafine $(<100 \mathrm{~nm})$ as well as accumulation $(>100 \mathrm{~nm})$ size range, while always important and of interest, have gained increasing attention (Buonanno et al., 2009; Chow et al., 2005; Kulmala et al., 2004a; McMurry, 2000; McMurry et al., 1996; Qian et al., 2007; Watson et al., 2006). Understanding potential hazards of nano particles will require the ability to determine not only their chemical nature but also their size, shape, and number. A standard dose metric for nano particles, whether surface area or particle number or some other quantity, would facilitate cross-comparisons between toxicity studies and exposure measurements (Su et al., 2008; Dall'Osto et al., 2008).

Nanotechnologies encompass broad interdisciplinary areas of research, development, and industrial activity that have been growing rapidly for the past decade. Disciplines include areas of physics, chemistry, biology, engineering, and electronics. Measuring as particles these entities that consist of

Published by Copernicus Publications on behalf of the European Geosciences Union. 
as few as $200-300$ molecules is also a significant challenge, both in terms of detection sensitivity and in terms of sample handling (Hinds, 1982; Brockman, 2001; Wang et al., 2002). Diffusion losses are inevitable in any measurement system involving sample lines, and will generally have a greater impact on the measured concentrations than on the mean particle size, but can also cause the measured size distribution to shift towards larger diameters. Such diffusion losses in the SMPS have been observed in experiments conducted with polydisperse $\mathrm{NaCl}$ aerosol in laboratory conditions (Frank et al., 2008). Losses were shown to occur in various parts of the Electrostatic Classifier. Other investigators have also found significant diffusion losses occurring within the Differential Mobility Analyzer (DMA) portion of the SMPS (Reineking and Porstendörfer, 1986; Rodrigue et al., 2007; Jeong and Evans, 2009).

In the atmosphere, the mechanisms of nano particle formation/growth remain a research topic of great interest (Zhang et al., 2004). Observations of enhanced particle number concentrations (or particle bursts) may be due to either new particle growth and formation; or to the transport of the particles to the observation site. The formation of ultrafine particles detected at a few $\mathrm{nm}$, and subsequent growth to $>50 \mathrm{~nm}$ in days, has been observed frequently (Dal Maso et al., 2005; Jeong et al., 2004; Kulmala et al., 2004b; Stanier et al., 2004). Competing with the formation and growth of new detectable particles is the condensation of clusters and gases onto pre-existing particles. This process is parameterized by a derived quantity called the condensation sink, which is a useful concept in the evaluation of atmospheric aerosol dynamics (Lehtinen et al., 2003).

This work presents measurements of particle number concentrations and size distributions obtained using two SMPSs: one with a Nano Differential Mobility Analyzer (Nano SMPS) and another with a long-tube Differential Mobility Analyzer (LDMA SMPS). Measurements were conducted at the sites of Whiteface Mountain (WFM, Summer 2002) and Pinnacle State Park (PSP, Summer 2004) in rural areas of New York State and at the urban site of Queens College (QC) in New York City in Summer 2001 and Winter 2004. The size distribution measurements were complemented by the total number concentration measurements obtained using co-located Condensation Particle Counters (CPC). This study provides a comprehensive picture of the evolution of the urban/rural aerosol and examines the physical processes leading to changes in the number size distribution and in the condensation sink.

\section{Experimental methods and data analysis}

\subsection{Measurement locations and periods}

Measurements of particle number concentrations and size distributions during four intensive field studies were per- formed using a stand-alone Condensation Particle Counter (CPC) and two Scanning Mobility Particle Sizers (SMPS). One of the SMPS instruments utilized a Nano Differential Mobility Analyzer (Nano SMPS) and with the other utilized a long-tube Differential Mobility Analyzer (LDMA SMPS). Table 1 summarizes operational parameters for the particle sizing and counting instruments. The Nano SMPS and LDMA SMPS were operated at Queens College (QC) in New York City from 3 July to 5 August in 2001 and from 10 January to 5 February in 2004; at Whiteface Mountain (WFM) from 10 July to 7 August in 2002 and at Pinnacle State Park (PSP) from 13 July to 6 August in 2004. These campaigns will be referred to as QC01, QC04, WFM02, PSP04, respectively.

Queens College (QC), the urban site, is located in a high population density section of New York City and has two busy highways nearby - the Long Island Expressway (I-495) and the Van Wyck Expressway (I-678). Whiteface Mountain (WFM) lodge site is halfway up the mountain at an elevation of about $600 \mathrm{~m}$ above sea level (a.s.l.), is surrounded by forest and mountains and located in the Adirondack Park of northern New York State. Pinnacle State Park (PSP), the other rural site, is at an elevation of about 500 meters asl and is located in southwestern New York in the low population density rural village of Addison, surrounded by light residential neighborhoods, parklands, and forested areas. Detailed descriptions of site operations and locations can be found elsewhere (Schwab et al., 2004, 2006).

\subsection{Condensation Particle Counter (CPC)}

A stand-alone Condensation Particle Counter (CPC, TSI Model 3022) was used to measure the number concentrations of particles at the four sampling sites. Instrument specifications indicate a 50\% detection efficiency for a particle diameter of $7 \mathrm{~nm}\left(D_{50}\right)$ and a $90 \%$ detection efficiency at particle diameter of $15 \mathrm{~nm}$. 5-min averaged concentrations were recorded during the QC01, QC04 and PSP04 campaigns, and 10 -s measurements were recorded during the WFM02 campaign (subsequently averaged to $5 \mathrm{~min}$ ). The CPC counts were corrected for diffusion losses in the sample lines before being compared to the SMPSs

\subsection{Scanning Mobility Particle Sizers (SMPSs)}

The Nano SMPS components were an Electrostatic Classifier (TSI Model 3080), Nano DMA (TSI Model 3085) and a CPC (TSI Model 3025). The LDMA SMPS consisted of an Electrostatic Classifier (TSI Model 3080), Long-tube DMA (TSI Model 3081) and a CPC (TSI Model 3010 or CPC 3025). Operational details for these instruments during the four campaigns are summarized in Table 1. 
Table 1. Operation parameters for the particle sizing and counting instruments.

\begin{tabular}{|c|c|c|c|}
\hline QC 01 & CPC 3022 & Nano SMPS & Long-tube SMPS \\
\hline Operator & $\mathrm{ASRC}^{\mathrm{a}}$ & $\mathrm{DEC}^{\mathrm{b}}$ & ASRC \\
\hline Cycle length, $\min$ & $5 \mathrm{~min}$ & 2.5 & $5(2$ scans of $2.5 \mathrm{~min})$ \\
\hline Inlet sample flow, $1 / \mathrm{min}$ & $0.3,1.5$ & 0.3 & $0.3,0.6,1.0$ \\
\hline Sheath flow, $1 / \mathrm{min}$ & N/A & 3 & $3.0,6.0,10.0$ \\
\hline Neutralizer Strength & N/A & $2 \mathrm{mCi}$ & $2 \mathrm{mCi}$ \\
\hline CPC Model & 3022 & 3025 & СРС 3010, СРС 3025 \\
\hline Diameter range, $\mathrm{nm}$ & $50 \%$ at $7 \mathrm{~nm} 90 \%$ at $15 \mathrm{~nm}$ & $4.7-160$ & Varied \\
\hline Number of Bins & N/A & 50 & Varied \\
\hline D (lower bound - upper bound) & N/A & $4.53-165.57$ & Varied \\
\hline WFM 02 & CPC 3022 & Nano SMPS & Long-tube SMPS \\
\hline Operator & ASRC & ASRC & ASRC \\
\hline Cycle length, $\min$ & 10 seconds & 5 (2 scans of $2.5 \mathrm{~min})$ & $5(2$ scans of $2.5 \mathrm{~min})$ \\
\hline Inlet sample flow, $1 / \mathrm{min}$ & 1.5 & $0.6+5.0$ bypass & 0.6 \\
\hline Sheath flow, $1 / \mathrm{min}$ & N/A & 6 & 6 \\
\hline CPC Model & 3022 & 3025 & 3010 \\
\hline Neutralizer Strength & N/A & $2 \mathrm{mCi}$ & $2 \mathrm{mCi}$ \\
\hline Diameter range, $\mathrm{nm}$ & $50 \%$ at $7 \mathrm{~nm} 90 \%$ at $15 \mathrm{~nm}$ & $3.28-104$ & $10.4-407$ \\
\hline Number of Bins & N/A & 49 & 52 \\
\hline D (lower bound - upper bound) & N/A & $3.16-107.52$ & $10.03-423.07$ \\
\hline QC 04 & СРC 3022 & Nano SMPS & Long-tube SMPS \\
\hline Operator & ASRC & $\mathrm{DEC}$ & ASRC \\
\hline Cycle length, $\min$ & $5 \mathrm{~min}$ & 2.5 & $5(2$ scans of $2.5 \mathrm{~min})$ \\
\hline Inlet sample flow, $1 / \mathrm{min}$ & 1.5 & 0.6 & 0.3 \\
\hline Sheath flow, $1 / \mathrm{min}$ & N/A & 6 & 3 \\
\hline CPC Model & 3022 & 3025 & 3010 \\
\hline Neutralizer Strength & N/A & $2 \mathrm{mCi}$ & $2 \mathrm{mCi}$ \\
\hline Diameter range, $\mathrm{nm}$ & $50 \%$ at $7 \mathrm{~nm} 90 \%$ at $15 \mathrm{~nm}$ & $3.28-104$ & $16-626$ \\
\hline Number of Bins & N/A & 49 & 52 \\
\hline D (lower bound - upper bound) & N/A & $3.16-107.52$ & $15.43-650.87$ \\
\hline PSP 04 & CPC 3022 & Nano SMPS & Long-tube SMPS \\
\hline Operator & ASRC & ASRC & ASRC \\
\hline Cycle length, min & $5 \min$ & $5(2$ scans of $2.5 \mathrm{~min})$ & $5(2$ scans of $2.5 \mathrm{~min})$ \\
\hline Inlet sample flow, $1 / \mathrm{min}$ & 1.5 & 0.3 & 0.3 \\
\hline Sheath flow, $1 / \mathrm{min}$ & N/A & 3 & 3 \\
\hline CPC Model & 3022 & 3025 & 3010 \\
\hline Neutralizer Strength & N/A & $2 \mathrm{mCi}$ & $2 \mathrm{mCi}$ \\
\hline Diameter range, $\mathrm{nm}$ & $50 \%$ at $7 \mathrm{~nm} 90 \%$ at $15 \mathrm{~nm}$ & $4.7-149$ & $16-626$ \\
\hline Number of Bins & N/A & 49 & 52 \\
\hline D (lower bound - upper bound) & N/A & $4.53-154.07$ & $15.43-650.87$ \\
\hline
\end{tabular}

a Atmospheric Sciences Research Center;

${ }^{\mathrm{b}}$ Department of Environmental Conservation.

\subsubsection{Diffusion loss for the sampling lines}

Sample line diffusion loss caused by particle deposition onto sample lines is expected. In order to estimate the diffusion losses in the sampling lines, an equation for circular tube penetration efficiency for aerosols was used (Hinds, 1982) and is discussed in more detail in the supplementary ma- terial (see http://www.atmos-chem-phys.net/10/4521/2010/ acp-10-4521-2010-supplement.pdf).

\subsubsection{Diffusion loss for the SMPS}

The diffusion losses are characterized in terms of total penetration, which for the SPMS is the product of the penetration 
for five composite flow paths through the SMPS: impactor inlet, bi-polar neutralizer and the internal plumbing, the tubing to the DMA and CPC, the DMA itself, and the CPC. Particle losses due to diffusion are more pronounced at lower flow rates and for smaller particles (Frank et al., 2008). A diffusion loss correction, which has recently been incorporated into a software module for the TSI SMPS (Aerosol Instrument Manager, ver 8.0, TSI, 2006) and allows particle size distributions for existing SMPS data to be recalculated to account for diffusion losses in the instrument, is applied for the Nano and LDMA SMPS datasets. Additional discussion of this correction, and the size dependent magnitude of the effect is presented in the supplementary material (see http://www.atmos-chem-phys.net/10/4521/2010/ acp-10-4521-2010-supplement.pdf).

\subsection{Condensation Sink (CS)}

The aerosol condensation sink (CS) is a measure of how rapidly molecules (and clusters) will condense onto preexisting aerosols (Dal Maso et al., 2002; Lehtinen et al., 2003; Pirjola et al., 1999).

An expression for the condensation sink (CS), with unit of $\mathrm{s}^{-1}$, describes the loss rate of molecules with diameter $d p$, diffusion coefficient $D$, onto a distribution $n\left(d_{p}\right)$ of $N i$ of existing aerosols. Thus, the CS can be calculated by integrating or summing over the size spectrum from SMPS data;

$\mathrm{CS}=2 \pi D \int_{0}^{\infty} d p \beta_{M}(d p) n(d p) d d p=2 \pi D \sum_{i} \beta_{M} i d p, i N i$

In Eq. (1), the diffusion coefficient $D$ is typically taken as that of $\mathrm{H}_{2} \mathrm{SO}_{4}$ in air (Hanson and Eisele, 2000), and the transitional correction factor $\beta_{M}$ can be expressed as (Fuchs and Sutugin, 1971);

$\beta_{M}=\frac{K n+1}{0.377 K n+1+\frac{4}{3} \partial^{-1} K n^{2}+\frac{4}{3} \partial^{-1} K n}$

In Eq. (2), $\partial=1$ is the sticking coefficient (Paul et al., 2004), and the Knudsen number $K n$ can be expressed in terms of particle diameter and the mean free path of vapor molecules $(\lambda v)$ as (Pirjola et al., 1999);

$K n=\frac{2 \lambda v}{d p}$

The pressure and temperature dependent mean free path $\lambda v$ in Eq. (3) can be determined from the following formula from Willeke (1976).

$\lambda v=\lambda r\left(\frac{101}{P}\right)\left(\frac{T}{293}\right)\left(\frac{1+110 / 293}{1+110 / T}\right)$

where $P$ is in $\mathrm{kPa}$ and $T$ in $\mathrm{K}$. At $293 \mathrm{~K}$ and 1 atmospheric pressure, the mean free path $\lambda r$ is $0.039 \mu \mathrm{m}$ for $\mathrm{H}_{2} \mathrm{SO}_{4}$. Using this reference value, $\lambda v$ can be determined for observed pressures and temperatures at the sampling sites. Using these values, and our measured size distributions, values for the condensation sink were computed for the four campaigns.

\section{Results and discussion}

\subsection{Relationship between Nano SMPS and LDMA SMPS}

Both the Nano SMPS and LDMA SMPS data presented here have been recalculated to include both diffusion loss correction for the sampling lines and diffusion loss correction for the SMPS. Since we want to combine the two SMPS systems to provide a full size distribution of sub-micron particles after the diffusion corrections, the first task is identifying a legitimate merge size point between the Nano SMPS and LDMA SMPS. Figure 1a shows how the merge size points were chosen. We calculated the coefficient of determination $\left(r^{2}\right.$ value) and slope for plots of counts from Nano and LDMA SMPS size bins centered on a range of mobility diameters from less than $30 \mathrm{~nm}$ to more than $80 \mathrm{~nm}$. For each campaign, the mean bin diameter corresponding to the largest $r^{2}$ value between the Nano and LDMA data sets was chosen as the merge point. A merge point of $62.6 \mathrm{~nm}$ was determined for the QC01, WFM02, and QC04 campaigns. A different merge point of $37.9 \mathrm{~nm}$ was determined for the PSP04 campaign by this method. We are not sure why a different merge point was determined for only one campaign, but there was for this campaign a noticeable discontinuity in mean value at $62.6 \mathrm{~nm}$; namely, the Nano SMPS data yielded concentrations in the size bin about $30 \%$ lower than LDMA data. If we were to choose $62.6 \mathrm{~nm}$ as the merge point for PSP04 campaign the total integrated number concentration from the combined SMPS measurements would be about 5\% lower.

As can be seen for Table 2, the size bins are basically identical in width and location for the Nano and LDMA systems in the overlap region. Figure $1 \mathrm{~b}$ shows the relationships between hourly averaged LDMA SMPS [62.6 nm] and Nano SMPS [62.6 nm] number concentrations for the QC01, WFM02, and QC04 campaigns, and between hourly averaged LDMA SMPS [37.9 nm] and Nano SMPS [37.9 nm] number concentrations for the PSP04 campaign. The linear correlations between Nano SMPS and LDMA SMPS yield good correlations $\left(r^{2}\right.$ of $>0.9$ ) for all campaigns except QC01 ( $r^{2}$ of 0.89 ). We attribute the lower correlation for the QC01 campaign to two factors: 1) the Nano SMPS and LDMA SMPS inlets were approximately $10 \mathrm{~m}$ from each other and the inlet designs were different for these measurements; and 2) the LDMA SMPS flow conditions were varied numerous times during the campaign. The correlations between merge point bins Nano SMPS and LDMA SMPS for QC01, WFM02, and PSP04 have slopes of 1.00, 0.96, and 0.97, respectively. The correlation for QC04 is significantly different from the other campaigns with a slope of 0.82. The Nano SMPS at the QC04 campaign yields higher values than the LDMA SMPS for sizes less than $100 \mathrm{~nm}$. We do not clearly understand why the QC04 Nano and LDMA data show poorer agreement than the other three campaigns, 
Table 2. Upper and Lower Limit at the Merge Size Points.

\begin{tabular}{llcccc}
\hline (Unit; nm) & & QC 01 $^{\mathrm{a}}$ & WFM 02 $^{\mathrm{a}}$ & QC 04 $^{\mathrm{a}}$ & PSP 04 $^{\mathrm{b}}$ \\
\hline Nano SMPS & Upper Limit & 64.98 & 64.98 & 64.98 & 39.26 \\
& Lower Limit & 60.46 & 60.46 & 60.46 & 36.54 \\
\multirow{2}{*}{ LDMA SMPS } & Upper Limit & 64.91 & 65.15 & 65.09 & 39.33 \\
& Lower Limit & 60.40 & 60.63 & 60.57 & 36.60 \\
\hline
\end{tabular}

${ }^{\mathrm{a}}$ Merge size point: $62.6{ }^{\mathrm{b}}$ merge size point: 37.9 .

but simply note that it was the only campaign that occurred during the winter.

\subsection{Relationship between SMPS and CPC total concentrations}

The hourly averaged SMPS $(8.35-283.9 \mathrm{~nm})$ with and without diffusion loss corrections and CPC data with diffusion loss correction were compared for all sampling periods. These pairwise correlations provide insight into the range of each measurement, allow comparisons between the instruments, and demonstrate the effect of recalculating the data to account for diffusion losses. Note that CPC data were corrected for the diffusion loss in the sampling lines as well, but since we have no size information from the CPC itself, we assumed the particles to have the same size distributions as Nano SMPS. Total averages of the diffusion losses for the CPC yield less than $4 \%$ losses for all four campaigns.

Figure 2 shows the pairwise correlation scatterplots for CPC and SMPS, and their corresponding average size distributions measured by the Nano SMPS for the (a) QC01, (b) WFM02, (c) QC04, and (d) PSP04 campaigns. One hour averages were calculated only for those hours for which $75 \%$ or more data were available.

The SMPS number concentrations (diffusion loss corrections both for the sampling lines and the SMPS, 8.35$283.9 \mathrm{~nm}$ ) and the CPC (diffusion loss correction for the sampling lines) number concentrations agree well for the four campaigns with linear regression slopes of 0.76-1.13 (forced to zero) and $r^{2}$ of $0.59-0.97$. The correlation values for the QC01 campaign are lower than those for the other campaigns due to varying sampling conditions as discussed previously. As seen in the Fig. 2, when the diffusion loss corrections are applied to the data, all four campaigns yield statistically significant (greater than 95\% confidence level) increases (closer to 1$)$ in the slope and correlation coefficient $\left(r^{2}\right)$. This is a strong indication that applying the diffusion loss corrections produced a better representation of the true ambient particle concentrations. (a)
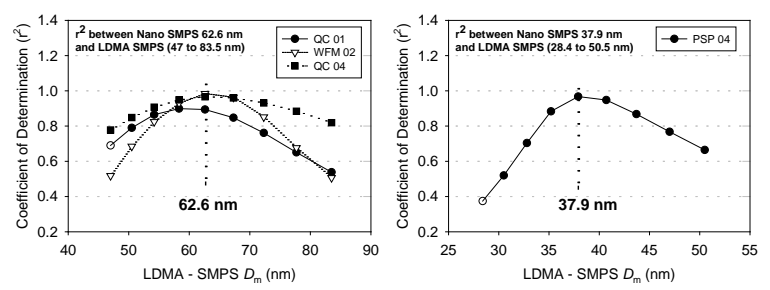

(b)
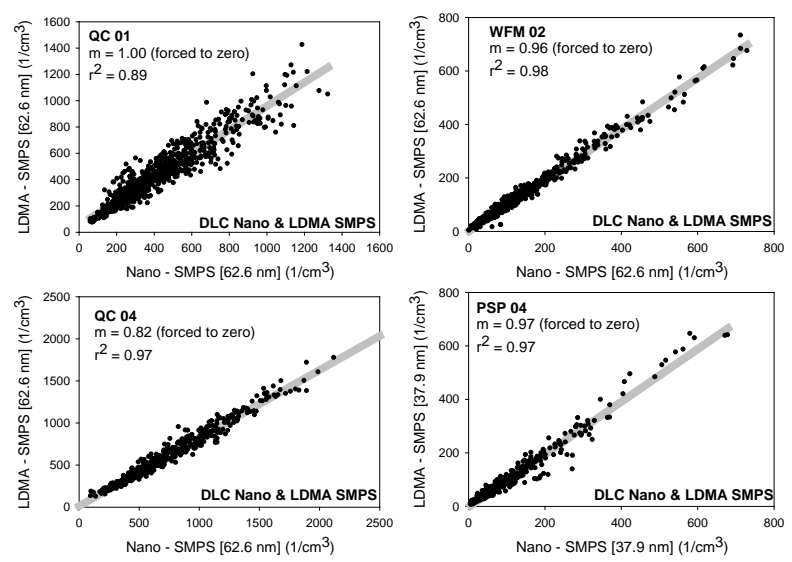

Fig. 1. Comparison of (a) coefficient of determination between Nano SMPS and LDMA SMPS at the QC01, WFM02, QC04, and PSP04 campaigns, (b) hourly averaged LDMA SMPS [62.6 nm] and Nano SMPS [62.6 nm] at the QC01, WFM02, and QC04 campaigns, respectively, hourly averaged LDMA SMPS [37.9 nm] and Nano SMPS $[37.9 \mathrm{~nm}]$ at the PSP04 campaigns.

\subsection{Nano particle size distributions at urban and rural locations in New York}

The right panels of Fig. 2 shows the average Nano SMPS size distributions measured by the Nano SMPS for the QC01, WFM02, QC04, and PSP04 campaigns. There are markedly different size distribution shapes (both before and after diffusion loss corrections) between the urban and rural locations. For the WFM02 campaign, the average number size distribution has a broad peak at about $50 \mathrm{~nm}$; while the PSP04 campaign distribution shows a gradual increase (and no clear mode in Nano SMPS). These features at the rural sites are the same both with and without diffusion loss corrections. 

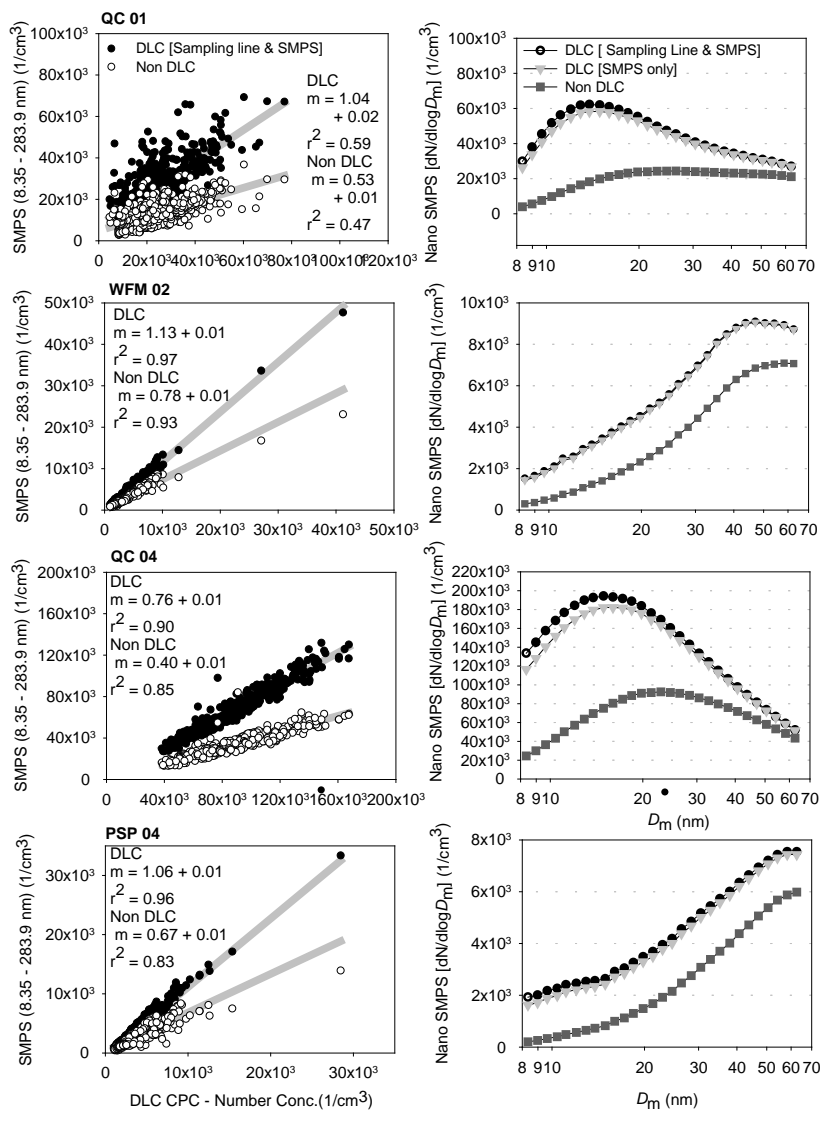

Fig. 2. Pairwise correlation scatterplots between hourly averaged diffusion loss corrected-DLC CPC and hourly averaged SMPS $(8.35-283.9 \mathrm{~nm})$ with number concentrations $\left(1 / \mathrm{cm}^{3}\right)$ corrected for diffusion loss and not corrected for diffusion loss, and Nano SMPS average size distributions $\left[d \mathrm{~N} / d \log D_{\mathrm{m}}\right]\left(1 / \mathrm{cm}^{3}\right)$ corrected for diffusion loss (solid circles) and not corrected for diffusion loss (open circles) for the QC01, WFM02, QC04, and PSP04 campaigns (note: $\mathrm{CPC}$ is assumed to have the same size distribution as Nano SMPS for diffusion loss correction).

However, for both the QC01 and QC04 campaigns, the average number size distribution has a clear mode at approximately $13 \mathrm{~nm}$ when corrected for diffusion loss. This is a significantly lower mode diameter than appears in the distribution prior to diffusion loss corrections, and is consistent with high primary emissions of particles at the QC site.

In general, for ambient aerosols at rural sites (WFM02 and PSP04), the diffusion loss corrections affect the absolute values of the particle concentrations but not the mode diameter or basic shape of the size distribution. For ambient aerosols at our urban campaigns (QC01 \& 04), the diffusion loss corrections affect both the absolute values of the particle concentrations and the basic shape of the size distribution. We believe these results show that diffusion loss corrections are always necessary for SMPS data gathered from urban as well as rural locations.

\subsection{Statistical characteristics of the measurements}

Figure 3 and Table 3 show the measurement locations and the statistical characteristics of hourly averaged number concentrations measured by CPC and diffusion loss corrected SMPS at the four sampling sites. The hourly average of CPC and SMPS number concentrations, rounded to three significant figures, are $22100 \pm 10700 \mathrm{l} / \mathrm{cm}^{3}$ (average \pm standard deviation) and $24100 \pm 107001 / \mathrm{cm}^{3}$ respectively for the QC01, and $87600 \pm 269001 / \mathrm{cm}^{3}$ and $66800 \pm 226001 / \mathrm{cm}^{3}$ respectively for QC04. Winter particle concentrations at QC are approximately four times higher than those from summer. Possible reasons for this seasonal difference include changes in vehicular emissions caused by cold starts during cooler parts of the year or increased residential heating and burning, and/or lower atmospheric boundary layer during the winter.

For the rural locations, the hourly averages of CPC concentrations are $3690 \pm 26301 / \mathrm{cm}^{3}(\max : 41200$; $\min$ : $977 \mathrm{l} / \mathrm{cm}^{3}$ ) and $3880 \pm 2200 \mathrm{l} / \mathrm{cm}^{3}$ (max: 28470; min: $1050 \mathrm{l} / \mathrm{cm}^{3}$ ) for WFM02 and PSP04, respectively. The largest particle number concentrations occur mainly in the ultrafine particle sizes and are associated with occasional daytime particle growth events (Zhang, et al., 2005). The binned size distributions shown in the inset Fig. 3 for each site show that the highest fraction of the total number concentration measured at the QC site is in the smallest size bin (8.35$19.8 \mathrm{~nm}$ ), while the WFM and PSP aerosol size distributions are characterized by maxima in the largest size bin (67.3$283.9 \mathrm{~nm}$ ). This difference can be attributed to occurrence of small fresh particles from primary emission for the QC campaigns and an enhancement of photochemical oxidation and condensational growth processes in aged air for the WFM02 and PSP04 campaigns.

\subsection{Time series size distributions, particle concentrations, and $\mathbf{P M}_{2.5}$ mass}

Figure 4 through 7 present complete time series traces for SMPS size distributions, CPC number concentrations, and $\mathrm{PM}_{2.5}$ mass concentrations by the Tapered Element Oscillating Microbalance (TEOM) (Schwab et al., 2006) during the four measurement campaigns (summertime for the QC01 campaign, wintertime for the QC04 campaign, summertime for the WFM02 campaign, and summertime for the PSP04 campaign). These time series plots provide insights into the range in particle size distributions, number concentrations, and $\mathrm{PM}_{2.5}$ mass concentrations (colored by approximate ion balance). The amounts of data available for each measurement allow initial validations. Data was flagged and removed from the analysis if any of the following conditions was known to apply: 1) when less than $75 \%$ of the data is available for an hour; 2) when an instrument was malfunctioning; or 3) when the data is an outlier based on statistical analysis such as extremely high values or zero values compared to before and after scans. Data completeness is about 
Table 3. Statistical characteristics of hourly averaged number concentrations measured by CPC and SMPS with diffusion loss corrections.

\begin{tabular}{|c|c|c|c|c|c|c|c|}
\hline SITE & Statistical Value & $\mathrm{CPC}$ & $8.35-283.9 \mathrm{~nm}$ & $8.35-19.8$ & $21.3-37.9$ & $40.7-62.6$ & $67.3-283.9$ \\
\hline \multirow[t]{6}{*}{ QC 01} & Valid (h) & 759 & 773 & 773 & 773 & 773 & 773 \\
\hline & Mean & 22124 & 24122 & 10871 & 6030 & 3355 & 3867 \\
\hline & Median & 19845 & 22022 & 9633 & 4928 & 3002 & 3643 \\
\hline & Std. Deviation & 10701 & 10668 & 5998 & 4036 & 1897 & 1819 \\
\hline & Minimum & 4,524 & 5,185 & 2,058 & 635 & 460 & 778 \\
\hline & Maximum & 77056 & 69324 & 42149 & 29358 & 12550 & 9543 \\
\hline \multirow[t]{6}{*}{ WFM 02} & Valid & 568 & 659 & 659 & 659 & 659 & 659 \\
\hline & Mean & 3691 & 4106 & 603 & 916 & 956 & 1631 \\
\hline & Median & 3122 & 3237 & 225 & 542 & 608 & 1490 \\
\hline & Std. Deviation & 2626 & 3231 & 1879 & 1186 & 909 & 981 \\
\hline & Minimum & 977 & 978 & 4 & 42 & 65 & 143 \\
\hline & Maximum & 41218 & 47685 & 39281 & 9659 & 5522 & 5385 \\
\hline \multirow[t]{6}{*}{ QC 04} & Valid & 650 & 431 & 431 & 431 & 431 & 431 \\
\hline & Mean & 87574 & 66760 & 35932 & 19516 & 7654 & 3,658 \\
\hline & Median & 84612 & 63058 & 32015 & 18021 & 6843 & 3120 \\
\hline & Std. Deviation & 26875 & 22579 & 14464 & 7526 & 3500 & 1985 \\
\hline & Minimum & 38290 & 27085 & 12282 & 6813 & 1534 & 777 \\
\hline & Maximum & 269160 & 163164 & 89978 & 49972 & 20993 & 12898 \\
\hline \multirow[t]{6}{*}{ PSP 04} & Valid & 587 & 564 & 564 & 564 & 564 & 564 \\
\hline & Mean & 3881 & 4052 & 520 & 690 & 980 & 1862 \\
\hline & Median & 3269 & 3450 & 277 & 422 & 726 & 1657 \\
\hline & Std. Deviation & 2201 & 2619 & 1078 & 983 & 813 & 1089 \\
\hline & Minimum & 1053 & 858 & 4 & 35 & 131 & 93 \\
\hline & Maximum & 28471 & 33380 & 17489 & 13472 & 5522 & 5881 \\
\hline
\end{tabular}

$95 \%, 97 \%, 66 \%, 95 \%$ measured by SMPS $(8.35-283.9 \mathrm{~nm}$ combined by Nano SMPS and LDMA SMPS) for the QC01, WFM02, QC04, and PSP04 campaigns, respectively. Lower data completeness for the QC04 campaign is mainly due to malfunctioning of the LDMA SMPS in the early part of the sampling period (10-14 January) and malfunction of Nano SMPS in the middle of the sampling period (24-26 January).

\subsection{Particle size distributions in the urban area}

The contour plots in Figs. 4 and 5 provide an overview of the evolution of the temporal particle size distributions and the time series line graphs show particle concentrations measured by the CPC and SMPS (summed over the size range of $8.35-283.9 \mathrm{~nm}$ ). The upper time series line graph is $\mathrm{PM}_{2.5}$ mass concentrations, colored by the major ion charge balance for the QC01 and QC04 campaigns. As seen from the graph panel showing binned number concentrations from SMPS, the majority of the measured particles reside in the "ultrafine mode" $\left(D_{\mathrm{m}}=10-100 \mathrm{~nm}\right)$ for the urban locations.

The contour plots from Figs. 4 and 5 show the concentration of particles in each size bin (in $d N / d \log D_{\mathrm{m}}\left(1 / \mathrm{cm}^{3}\right)$ ). The logarithmic vertical axis is the particle diameter $\left(D_{\mathrm{m}}\right)$, and horizontal axis is the time during a sampling period. The particle number concentrations are shown by the color with highest concentrations being the hottest color. The characteristic feature of both QC01 and QC04 data sets is a daily diurnal pattern in a form of a gradual increase from the early morning and a decrease in late morning, consistent with vehicle emissions particle sources. The high particle concentration events are consistently associated with the morning traffic. The mean particle size during these events is between 8.35 to $19.8 \mathrm{~nm}$ for the QC01 and the QC04 campaign. The size range of $8.35-19.8 \mathrm{~nm}$ accounts for about $45 \%$ of the total number concentration measured by the SMPS [8.35$283.9 \mathrm{~nm}]$ for the QC01 campaign and about $54 \%$ for the QC04 campaign. Particularly for the wintertime QC04 campaign, the morning rush hour traffic occurs prior to the lifting of the nighttime inversion and fresh emissions remain near the boundary layer sampled by these measurements. The evening rush hour is not readily discernable, due at least in part to the expanded boundary layer later in the day. The Figs. 4 and 5 show that there is no discernable difference in measured size distributions between weekdays (Monday to Friday) and weekends (Saturday to Sunday) for the QC01 and QC04 campaigns.

Figures 4 and 5 also show time series traces for the hourly number concentration $\left(1 / \mathrm{cm}^{3}\right)$ measured by the CPC. 


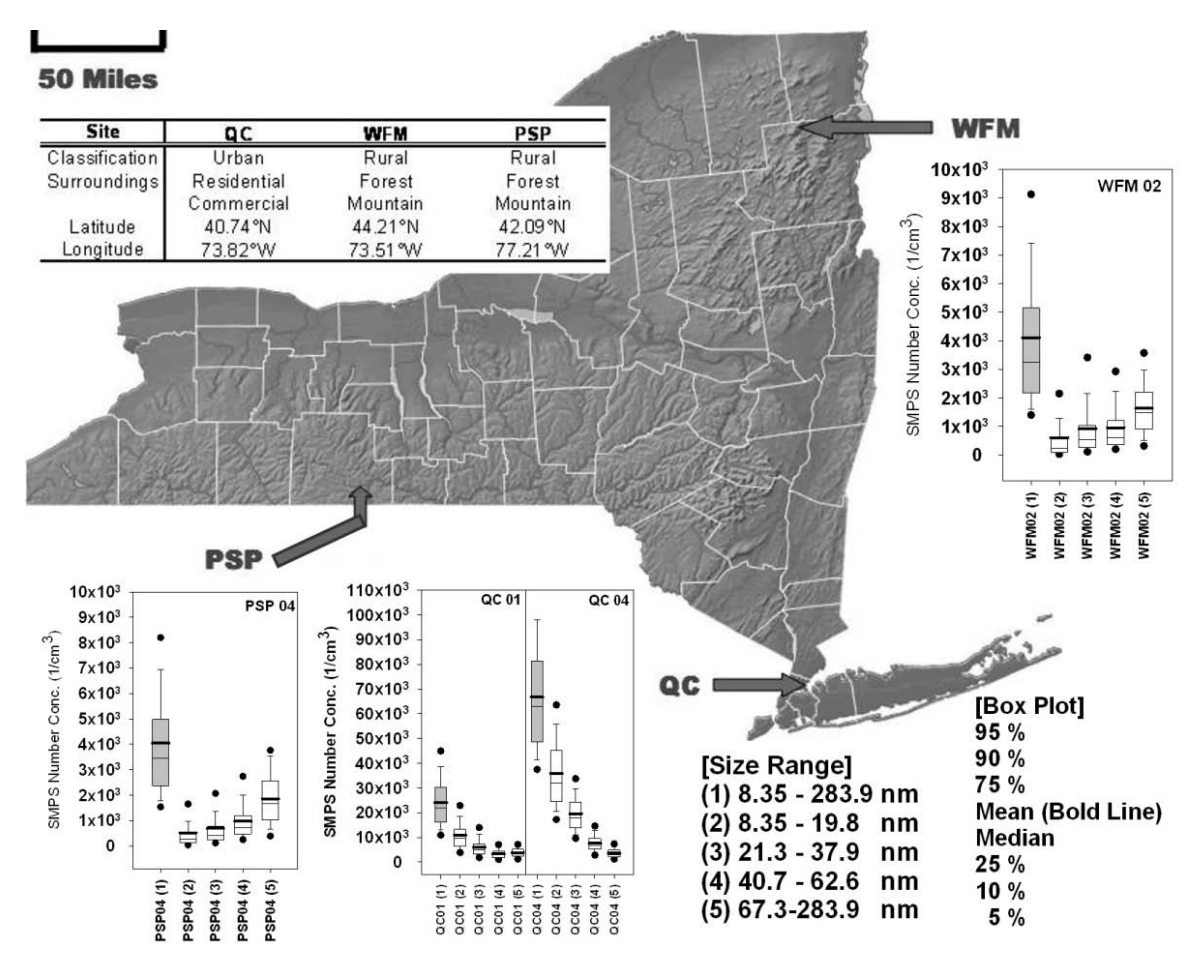

Fig. 3. Location of sampling sites and number concentrations by SMPS from Pinnacle State Park (PSP), Whiteface Mountain (WFM) and Queens College (QC) in New York (the bold line inside the box is the mean value; the boundary of the box closest to zero is the 25th percentile; the thin line inside the box is the median and the boundary of the box farthest from zero is the 75th percentile. Whiskers correspond to the 10th and 90th percentiles. Upper and lower closed dots correspond to the 5th and 95th percentiles).
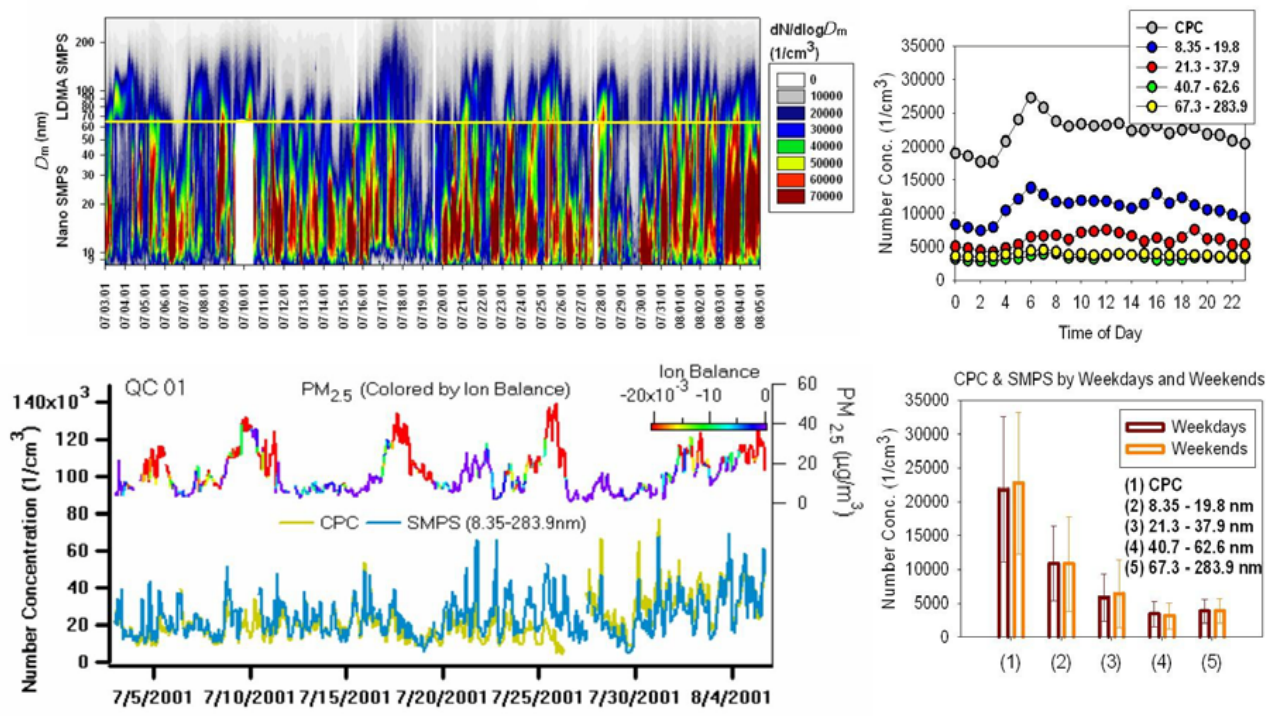

Fig. 4. Evolution of particle size distributions and particle concentrations $\left[d \mathrm{~N} / d \log D_{\mathrm{m}}\right]\left(1 / \mathrm{cm}^{3}\right)$, time series traces for the hourly number concentration $\left(1 / \mathrm{cm}^{3}\right)$ measured by the CPC (dark yellow line) and SMPS [8.35-283.9 nm] (dark blue line), as well as PM 2.5 mass concentrations (colored by the ion charge balance), hour-of-day series by CPC (gray) and SMPS (8.35-19.8 nm: blue, 21.3-37.9: red, 40.7-62.6: green, 67.3-283.9: yellow) and weekdays (brown) and weekends (orange) in number concentrations for the QC01. 

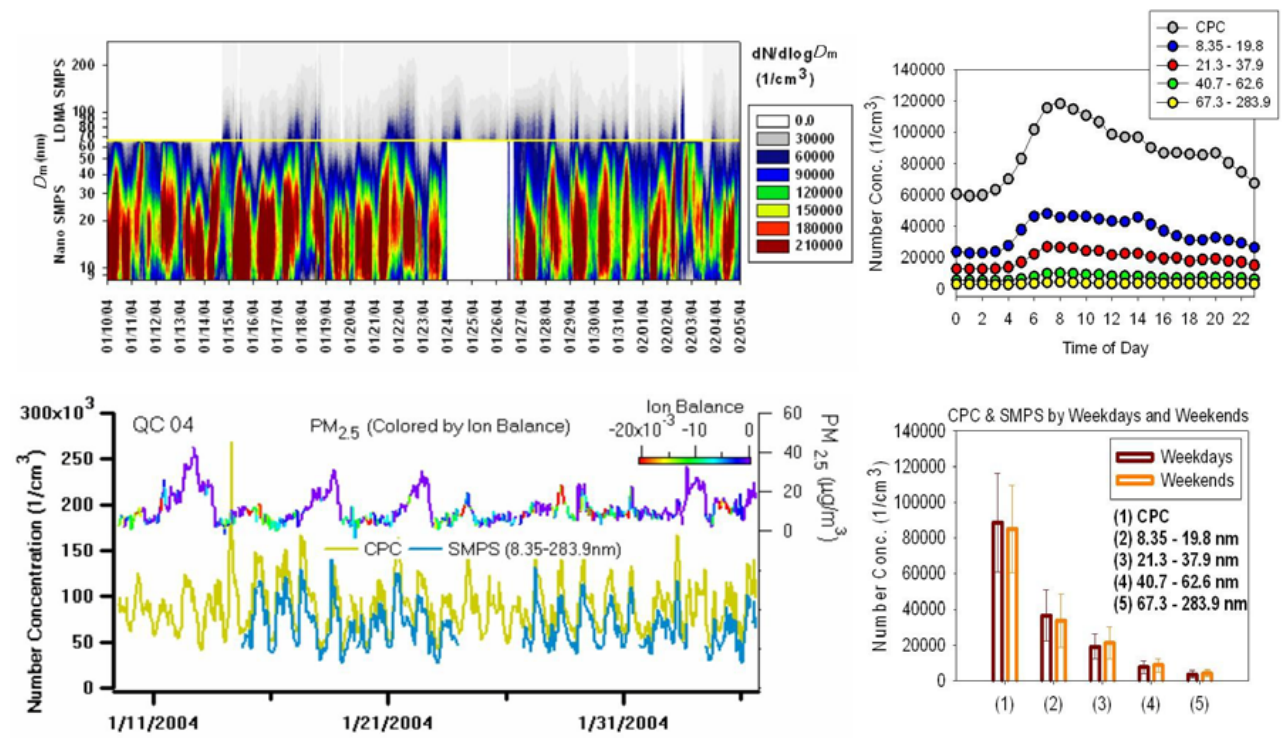

Fig. 5. Evolution of particle size distributions and particle concentrations $\left[d \mathrm{~N} / d \log D_{\mathrm{m}}\right]\left(1 / \mathrm{cm}^{3}\right)$, time series traces for the hourly number concentration $\left(1 / \mathrm{cm}^{3}\right)$ measured by the CPC (dark yellow line) and SMPS [8.35-283.9 nm] (dark blue line), as well as PM $2.5 \mathrm{mass}$ concentrations (colored by the ion charge balance), hour-of-day series by CPC (gray) and SMPS (8.35-19.8 nm: blue, 21.3-37.9: red, 40.7-62.6: green, 67.3-283.9: yellow) and weekdays (brown) and weekends (orange) in number concentrations for the QC04.

The number concentrations of "combined SMPS" [8.35$283.9 \mathrm{~nm}$ ] and the CPC track each other well during periods of low concentrations and during traffic activities. Linear regression slopes for the above between these two parameters result in correlations slopes of 0.76 and 1.04 (forced to zero) and $r^{2}$ values of 0.59 and 0.90 as previously shown in Fig. 2.

\subsection{Particle size distributions in the rural areas}

Figures 6 and 7 show an overview of the evolution of the temporal particle size distributions, and particle concentrations and $\mathrm{PM}_{2.5}$ mass concentrations for the WFM02 and PSP04 campaigns. The binned particle concentrations from the SMPS for the WFM02 and PSP04 campaigns show very different distributions than observed in New York City. While the particles are in all size ranges ("nucleation mode" $\left(D_{\mathrm{m}}=<10 \mathrm{~nm}\right)$, "ultrafine mode" $\left(D_{\mathrm{m}}=10-100 \mathrm{~nm}\right)$ and "accumulation mode" $\left.\left(D_{\mathrm{m}}=>100 \mathrm{~nm}\right)\right)$, the largest fraction of particles in the rural campaigns was found in the size range of 67.3-283.9 nm (about $40 \%$ of the total number concentrations for the WFM02 campaign and about $46 \%$ for the PSP04 campaign).

Evident in the color contour plots of Figs. 6 and 7 for both sites is one or more particle growth events, with high particle concentrations down to the lowest particle diameters. The two strongest growth events occurred on 24 July (Wednesday) for the WFM02 campaign and, same date but different year, on 24 July (Saturday) for the PSP04 campaign, in each case beginning in the early to mid-morning time and extending through the afternoon and evening into the next day.
These strong particle growth events will be discussed in the next section.

Excluding these particle growth days, no distinguishable daily diurnal pattern has been observed in the signals from either rural area. In addition, there is no discernable difference in measured size distributions between weekdays and weekends for the WFM02 and PSP04 campaigns without the particle growth days. The number concentrations between the combined SMPS [8.35-283.9 nm] and the CPC track each other well during periods of low concentrations as well as particle growth events with linear regression slopes of 1.131.06 (forced to zero) and $r^{2}$ of 0.96-0.97 (Fig. 2).

\subsection{Particle growth events at the rural site}

A number of groups have observed particle formation and growth events in a variety of locations including rural and urban areas (Jeong, et al., 2006; Watson, et al., 2006; Zhang, et al., 2005). In these events there is a "burst" of nanoparticles $(<10 \mathrm{~nm})$ in ambient air that grow quickly into ultrafine $(10$ to $100 \mathrm{~nm})$ and accumulation $(100$ to $1000 \mathrm{~nm})$ modes, then persist for several days (Kulmala, et al., 2004).

During the measurement periods at the rural sites, one very strong particle formation and growth event with very high concentrations down to the lowest reported diameter of $8 \mathrm{~nm}$ was observed for each site. We have analyzed these events in some detail and present a summary of the observations here; additional details are presented in the supplementary material. Just before the event we observed low particle concentration and $\mathrm{PM}_{2.5}$ mass, and particles that were largely 

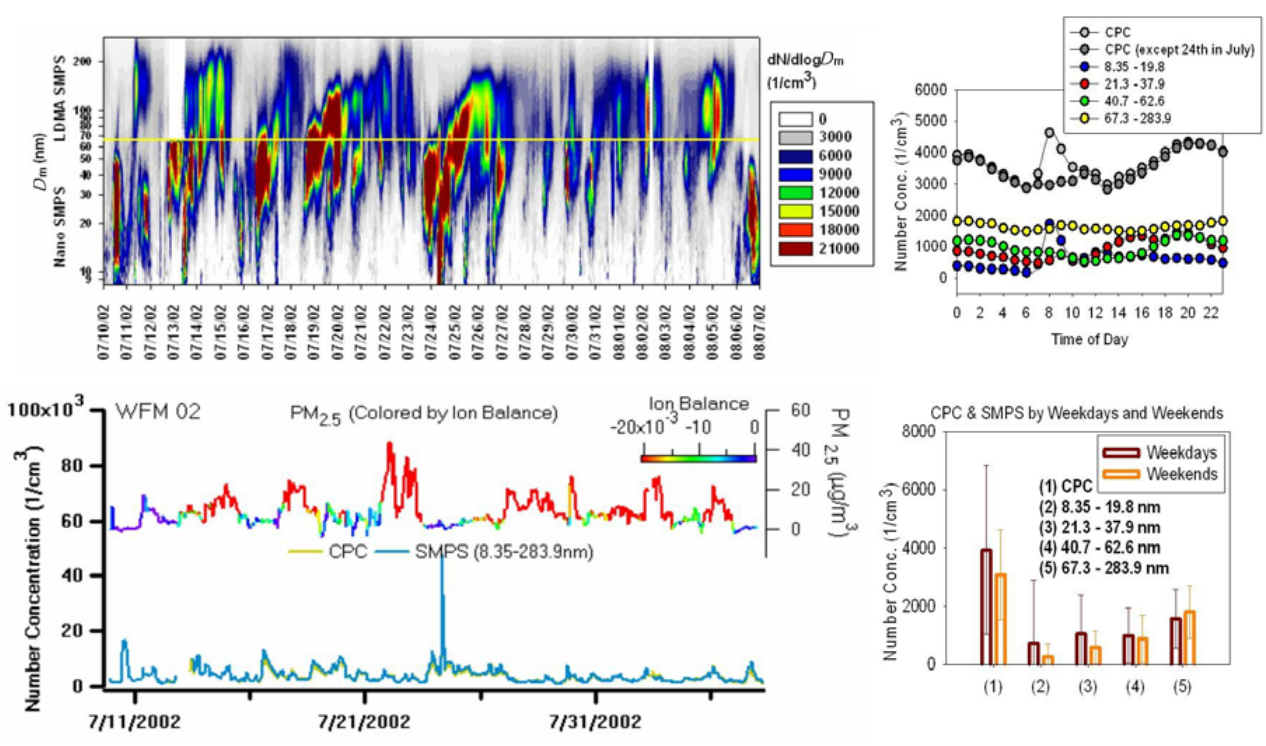

Fig. 6. Evolution of particle size distributions and particle concentrations $\left[d \mathrm{~N} / d \log D_{\mathrm{m}}\right]\left(1 / \mathrm{cm}^{3}\right)$ and time series traces for the hourly number concentration $\left(1 / \mathrm{cm}^{3}\right)$ measured by the CPC (dark yellow line) and SMPS [8.35-283.9 nm] (dark blue line), as well as PM 2.5 mass concentrations (colored by the ion charge balance), hour-of-day series by CPC (gray) and SMPS (8.35-19.8 nm: blue, 21.3-37.9: red, 40.7-62.6: green, 67.3-283.9: yellow) and weekdays (brown) and weekends (orange) in number concentrations for the WFM02.
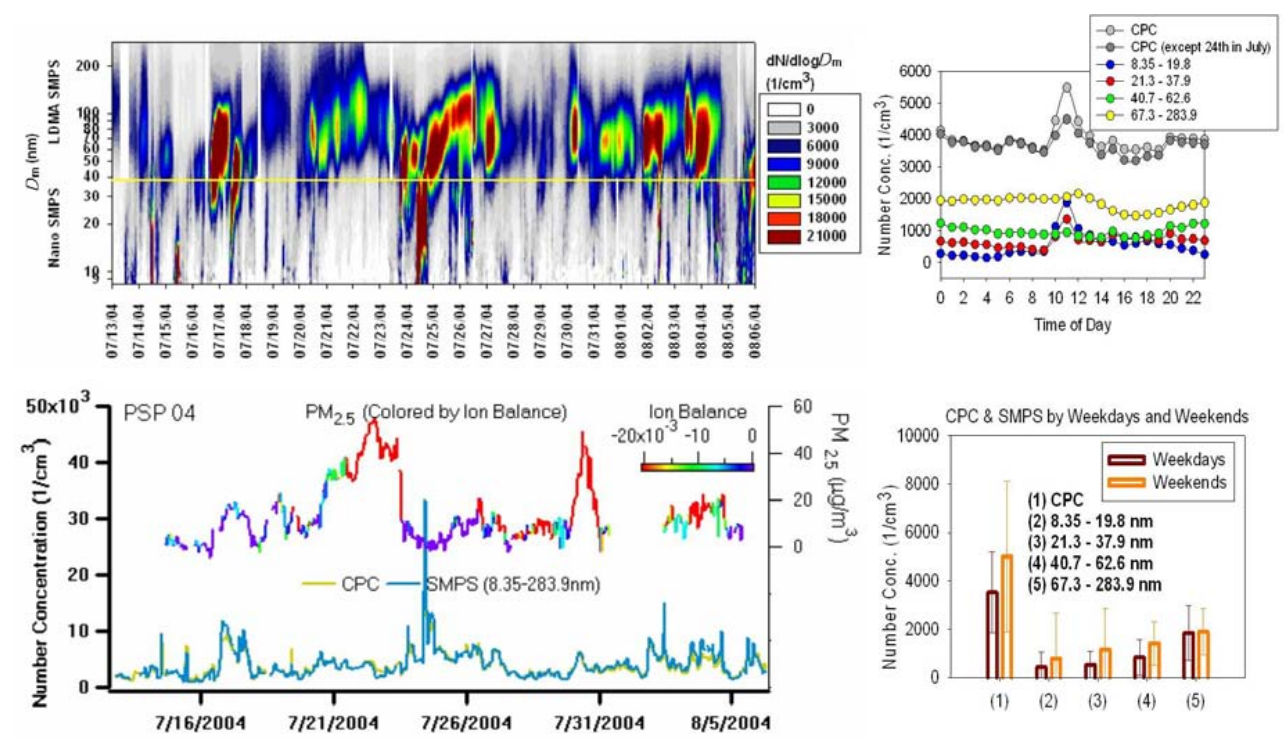

Fig. 7. Evolution of particle size distributions and particle concentrations $\left[d \mathrm{~N} / d \log D_{\mathrm{m}}\right]\left(1 / \mathrm{cm}^{3}\right)$ and time series traces for the hourly number concentration $\left(1 / \mathrm{cm}^{3}\right)$ measured by the CPC (dark yellow line) and SMPS [8.35-283.9 nm] (dark blue line), as well as PM $2.5 \mathrm{mass}$ concentrations (colored by the ion charge balance), hour-of-day series by CPC (gray) and SMPS (8.35-19.8 nm: blue, 21.3-37.9: red, 40.7-62.6: green, 67.3-283.9: yellow) and weekdays (brown) and weekends (orange) in number concentrations for the PSP04.

neutralized. The onset coincides with an increase in $\mathrm{SO}_{2}$, but not in $\mathrm{CO}, \mathrm{NO}$, or $\mathrm{NO}_{2}$. The particle size distribution shifts to large concentrations of very small particles, and shifts over the next hours to fewer, larger particles. These observations are all similar to those seen by other groups (Jeong et al., 2006; Watson et al., 2006; Zhang et al., 2005). The com- bined effects of clean, cool air combined with elevated $\mathrm{SO}_{2}$ and sunlight to drive sulfuric acid formation, and possibly including some mixing from aloft of condensable species seem to be common characteristics of summer time growth events. Note that these events are not common during the middle of the summer at these locations, but relatively infrequent. This 

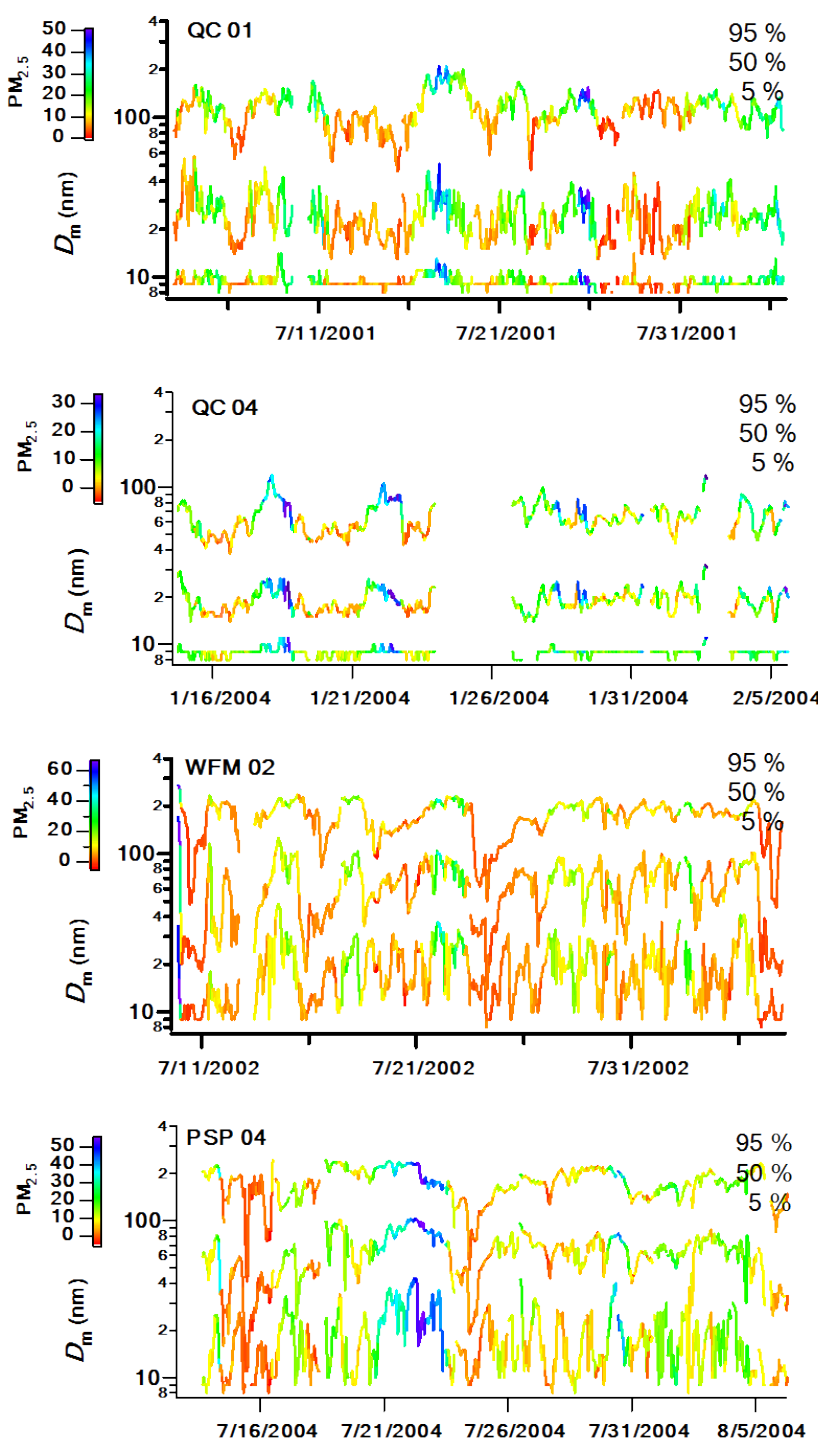

Fig. 8. Time series traces for the $95 \%, 50 \%, 5 \%$ of the particle size diameter $(\mathrm{nm})$ measured by the SMPS $[8.35-283.9 \mathrm{~nm}]$ colored by $\mathrm{PM}_{2.5}$ mass concentrations $\left(\mu \mathrm{g} / \mathrm{m}^{3}\right)$ for the QC01, QC04, WFM02, and PSP04 campaigns.

observation is consistent with the observations in Kulmala et al. (2004b), but different from the conclusions of Zhang et al. (2005) and Stanier et al. (2004). We also calculated the growth rates of the mode diameter of the particles for these two events. These events are clearly visible in Fig. 8 as periods when there is first a sharp drop in particle diameter, followed by a sharp rise in diameter. The growth rates computed as $\Delta D_{\text {mode }} / \Delta t$ (where $D_{\text {mode }}$ is the mode particle diameter) over a roughly $36 \mathrm{~h}$ period yielded $2.8 \mathrm{~nm} /$ hour for the strong WFM02 event and $2.4 \mathrm{~nm} /$ hour for the strong PSP04 event.

\subsection{Periods of high particle concentrations at the urban site}

As noted in Sect. 3.6, the urban measurements show a consistent burst of small particles daily without the clear periods of extended growth seen at the rural sites. The mean diameters during the urban high concentration periods are $15-25 \mathrm{~nm}$ during the winter, and $20-30 \mathrm{~nm}$ during the summer. There is a consistent morning peak, as noted before, and a much less pronounced evening enhancement. Nucleation will occur at the urban site, but strong primary sources - leading to a larger condensation sink (see below) render this process to a much smaller role than at the rural sites.

\subsection{Relationship between $\mathbf{P M}_{2.5}$ mass and particle size diameter}

Figure 8 presents time series of the median particle size diameter $(\mathrm{nm})$, and the 5th and 95th percentile diameters colored as a function of the $\mathrm{PM}_{2.5}$ mass concentrations. The higher mass concentrations were measured simultaneously with the higher particle diameters; and as we have seen, mass concentrations are generally anti-correlated with number concentrations. These observations can be explained by considering two limiting cases. The low mass loading limiting case is generally accompanied by observations of low $\mathrm{PM}_{2.5}$ mass, high number concentration, and small mean diameter caused by the occurrence of "small fresh particles" associated with two possible processes; 1) recent primary emission (as observed for the QC01 and QC04 campaigns) associated with Black Carbon (BC) or hydrocarbon-like organic aerosol (HOA), or 2) particle nucleation and growth associated with sulfuric acid by sulfur dioxide and sulfate (Jung et al., 2006) (as observed for the WFM02 and PSP04 campaigns). The high mass loading limiting case is accompanied by observation of high $\mathrm{PM}_{2.5}$ mass, lower number concentration, and larger mean diameter. These episodes are mainly due to an enhancement of oxidation and condensation processes in relatively "aged air". These observations have also important implications, from a technical point of view, for urban/rural air quality monitoring. Specifically, number concentrations and $\mathrm{PM}_{2.5}$ mass exhibit some properties which are complementary for monitoring the urban/rural air quality. Number concentration is highly sensitive to the fresh vehicle exhaust emissions of ultrafine particles, whereas $\mathrm{PM}_{2.5}$ mass is highly influenced by the aged aerosol linked to the urban background mostly occurring in the accumulation mode due to the atmospheric processing of vehicle emissions and other sources as shown in Figs. 4-7.

\subsection{Relationship between $\mathbf{P M}_{2.5}$ mass and Condensation Sink (CS)}

In order to understand the dynamic effects of aerosol growth for the QC 01, WFM02, QC 04 and PSP04 campaigns, the 


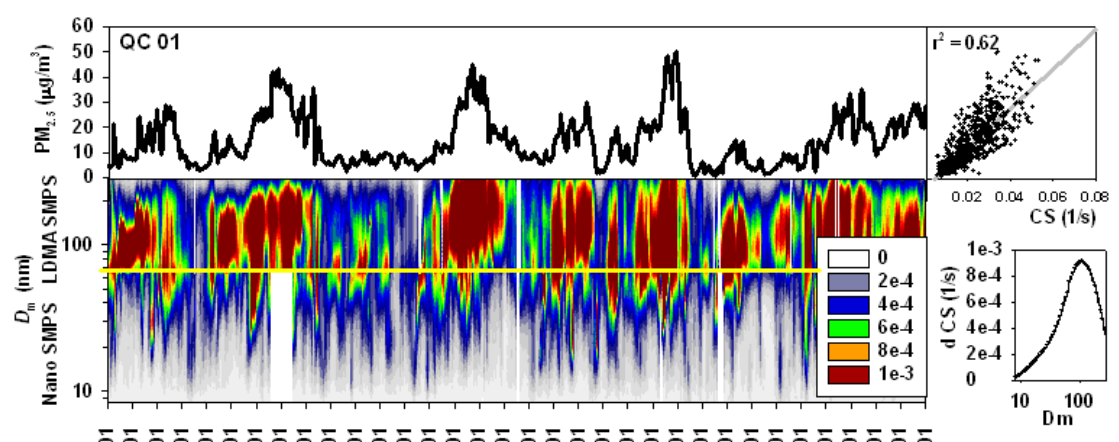

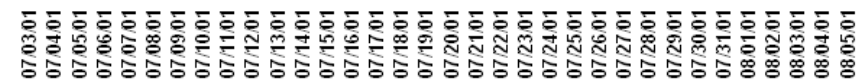

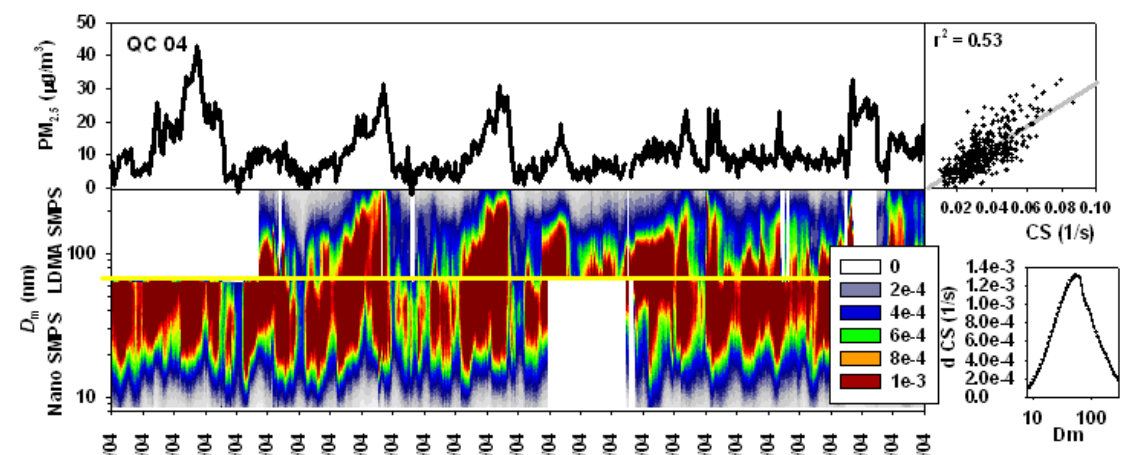

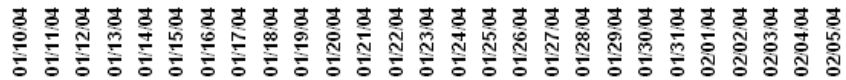

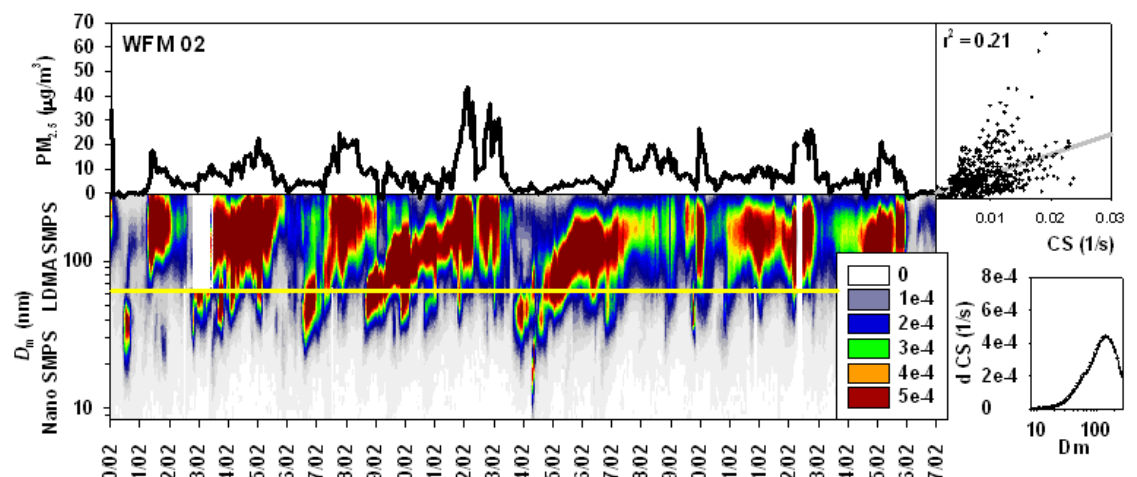

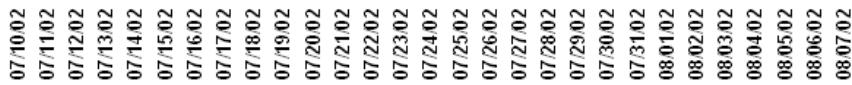

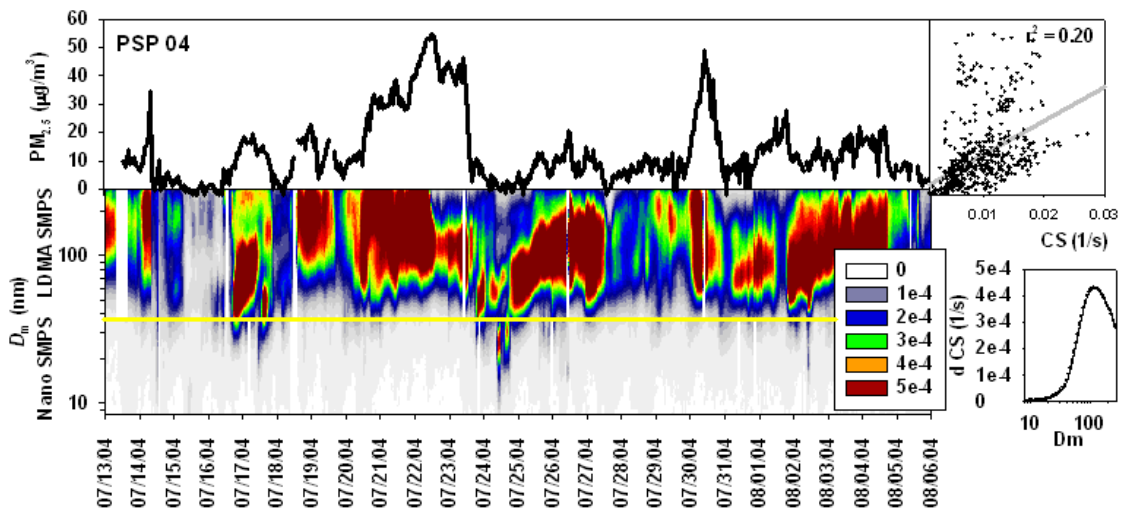

Fig. 9. Evolution of size dependent contributions to the condensation sink (1/s), time series traces for the hourly $\mathrm{PM}_{2.5} \mathrm{mass}$ concentration $\left(\mu \mathrm{g} / \mathrm{cm}^{3}\right)$, and pairwise correlation scatterplots between $\mathrm{PM}_{2.5}$ mass concentration and condensation sink for the QC 01 , QC 04 , WFM 02 and PSP 04. 
condensation sink (CS) was calculated as described earlier. Dal Maso et al. (2002) observed values for the CS of 4$7 \times 10^{-3} \mathrm{~s}^{-1}$ in the rural (forest) area and $2 \times 10^{-3} \mathrm{~s}^{-1}$ under coastal conditions. Kulmala et al. (2005) observed values of the CS between $1.3 \times 10^{-2}$ and $0.6 \times 10^{-4} \mathrm{~s}^{-1}$ in a variety of locations. The CS was usually higher in more polluted areas $\left(5-7 \times 10^{-2} \mathrm{~s}^{-1}\right)$ encountered in New Delhi, while Athens and Marseille CS in the European cities was 5-10 times lower. Leskinen et al. (2008) also showed values of $1.4-13 \times 10^{-3} \mathrm{~s}^{-1}$ in a smog chamber study.

The averages ( \pm standard deviation) of the CS $(8.35-$ $283.9 \mathrm{~nm})$ yielded $2.3( \pm 0.9) \times 10^{-2}, 8.7( \pm 4.4) \times 10^{-3}, 3.5$ $( \pm 1.3) \times 10^{-2}$, and $9.2( \pm 4.7) \times 10^{-3}(1 / \mathrm{s})$ for the QC 01 , WFM02, QC 04 and PSP04 campaigns, respectively. The CS in the urban areas is roughly two to three times higher than rural areas due to differences in number concentrations and size distributions.

Figure 9 presents evolutions of the size dependent contributions to the CS $(1 / \mathrm{s})$ and the time series of the hourly $\mathrm{PM}_{2.5}$ mass concentrations $\left(\mu \mathrm{g} / \mathrm{cm}^{3}\right)$. The top right panels of Fig. 9 show the pairwise correlation scatterplots between $\mathrm{PM}_{2.5}$ mass and CS for the four campaigns. There are markedly different relationships between the urban and rural locations. While there is a good relationship $\left(r^{2}>0.5\right)$ between $\mathrm{PM}_{2.5}$ mass and CS in the urban areas, there is a less clear association with low $r^{2}$ of 0.21 and 0.20 for the WFM02 and PSP04 campaigns, respectively. The stronger relationship between $\mathrm{PM}_{2.5}$ mass and $\mathrm{CS}$ in the urban areas can be explained by the large contribution to $\mathrm{PM}_{2.5}$ mass by dynamic condensation processes from primary emissions for the urban site. For the rural areas, the scatterplots indicate a more complicated picture. The two strongest growth events produce relatively high CS values without large $\mathrm{PM}_{2.5}$ mass, but other data periods show poor association between CS and $\mathrm{PM}_{2.5}$ mass. The lower right panels in Fig. 9 show the average contribution to the CS for the SMPS size bins. The peak contribution to the CS for all three summer campaigns occurs near $100 \mathrm{~nm}$, while for the winter campaign, with higher particle concentrations and smaller diameters, the peak contribution to the CS occurs closer to $60 \mathrm{~nm}$.

\section{Summary and conclusions}

This study presents measurements of particle number concentrations and size distributions using combined data from a Nano SMPS and an LDMA SMPS. Measurements were conducted at the sites of Whiteface Mountain (WFM, Summer 2002) and Pinnacle State Park (PSP, Summer 2004) in rural areas of New York State and at the urban site of Queens College (QC) in New York City in Summer 2001 and Winter 2004.

We have analyzed the size distributions with and without corrections for the diffusion losses of particles, both in the inlet sampling lines, and in the SMPS systems. We showed that inclusion of these corrections is important for nano par- ticle concentration and size distribution measurements. The diffusion correction uncovers a nano particle mode between 10 and $15 \mathrm{~nm}$ mobility diameter which is not present in the uncorrected data for the measurements in New York City. Slopes of scatterplots between the total number concentrations measured by a stand alone CPC and the integrated total number concentration from the combined SMPS measurements range from 0.76 to 1.13 , and $r^{2}$ values for three of the four campaigns are 0.90 or above (the $r^{2}$ value for the QC01 campaign is 0.59).

The New York City measurements show a daily pattern of high total number concentrations in the morning hours associated with the morning rush hour and traffic emissions. Winter concentrations average about four times greater than summer concentrations at the Queens site. The rural sites have average summer concentrations that are about a factor of 5-6 lower than the Queens summer concentrations. The rural summer size distributions have much larger mode diameters, with largest concentrations in the accumulation mode. Analysis of the characteristics of particle growth in comparison to other observations allow classification of the events and illustrate that particle growth contains different physical behavior related to different compounds.

Low $\mathrm{PM}_{2.5}$ mass quite often is associated with high number concentration and small particle diameter in our observations. These associations are caused by the occurrence of small fresh particles associated with primary emission (for the QC01 and QC04 campaigns), or by fresh particle nucleation and growth (for the WFM02 and PSP04 campaigns). In contrast, the observations of high $\mathrm{PM}_{2.5}$ mass, is often associated with lower number concentration and larger diameter, which we believe indicate an enhancement of condensation processes in photochemically aged air. There are markedly different values for the calculated condensation sink between the urban and rural locations, with campaign averages between $8.7 \times 10^{-3}-9.2 \times 10^{-3} \mathrm{~s}^{-1}$ for the rural sites, and $2.3 \times 10^{-2}-3.5 \times 10^{-2} \mathrm{~s}^{-1}$ for the urban site. The condensation sink has a strong association with $\mathrm{PM}_{2.5}$ mass for the New York City site, but a much weaker relation with $\mathrm{PM}_{2.5}$ mass at the rural sites.

Acknowledgements. This work was supported by NOAA award number NA05OAR4310105, by the New York State Energy Research and Development Authority (NYSERDA) contracts 4918ERTERES99, 5060ERTERER99, and 6183; and by EPA cooperative agreement \#R828060010; and New York State Department of Environmental Conservation (NYSDEC) contract \#C004210. Although the research described in this article has been funded in part by EPA, it has not been subjected to the agency's required peer and policy review and, therefore, does not necessarily reflect the views of the agency and no official endorsement should be inferred. Helpful discussion and the assistance of ASRC scientists Qi Zhang, John Spicer, Fangqun Yu, as well as Silke Weimer at EMPA, and Dirk Felton at DEC are gratefully acknowledged.

Edited by: S. Pandis 


\section{References}

Brockman, J. E.: Sampling and Transport of Aerosols; in Aerosol Measurement: Principles, Techniques, and Applications, 2nd. Edition, edited by: Baron, P. A. and Willeke, K., John Wiley \& Sons, NJ, 2001.

Bae, M.-S., Schwab, J. J., Zhang, Q., Hogrefe, O., Demerjian, K. L., Weimer, S., Rhoads, K., Orsini, D., Venkatachari, P., and Hopke, P. K.: Interference of Organic Signals in Highly-time Resolved Nitrate Measurements by Aerosol Mass Spectrometer, J. Geophys. Res., 112, D22305, doi:10.1029/2007JD008614, 2007.

Buonanno, G., Lall, A. A., and Stabile, L.: Temporal size distribution and concentration of particles near a major highway, Atmos. Environ., 43, 1100-1105, 2009.

Chow, J. C., Watson, J. G., Savage, N., Solomon, C. J., Cheng, Y.S., McMurry, P. H., Corey, L. M., Bruce, G. M., Pleus, R. C., Biswas, P., and Wu, C.-Y.: Nanoparticles and the Environment, J. Air Waste Manage. Assoc., 55, 1411-1417, 2005.

Dal Maso, M., Kulmala, M., Riipinen, I., Wagner, R., Hussein, T., Aalto, P.P., and Lehtinen, K. E. J.: Formation and growth of fresh atmospheric aerosols: eight years of aerosol size distribution data from SMEAR II, Hyytiälä, Finland, Boreal Environ. Res., 10, 323-336, 2005.

Dal Maso, M., Kulmala, M., Lehtinen, K. E. J., Mäkelä, J. M., Aalto, P., and O'Dowd, C. D.: Condensation and coagulation sinks and formation of nucleation mode particles in coastal and boreal forest boundary layers, J. Geophys. Res., 107, 8097, doi:10.1029/2001JD001053, 2002.

Dall'Osto, M., Booth, M. J., Smith, W., Fisher, R., and Harrison, R. M.: A Study of the Size Distributions and the Chemical Characterization of Airborne Particles in the Vicinity of a Large Integrated Steelworks, Aerosol Sci. Technol., 42, 981-991, 2008.

Frank, B. P., Saltiel, S., Hogrefe, O., Grygas, J., and Garland Lala, G.: Determination of mean particle size using the electrical aerosol detector and the condensation particle counter: Comparison with the scanning mobility particle sizer, J. Aerosol Sci., 39, 19-29, 2008.

Drewnick, F., Schwab, J. J., Jayne, J. T., Canagaratna, M., Worsnop, D. R., and Demerian, K. L.: Measurement of Ambient Aerosol Composition During the PMTACS-NY 2001 Using an Aerosol Mass Spectrometer. Part I: Mass Concentrations, Aerosol Sci. Technol., 38, 92-103, 2004.

Fuchs, N. A. and Sutugin, A. G.: Highly dispersed aerosol, in: Topics in Current Aerosol Research, edited by: Hidy, G. M. and Brock, J. R., Pergamon, New York, 1-60, 1971.

Hanson, D. R. and Eisele, F.: Diffusion of $\mathrm{H}_{2} \mathrm{SO}_{4}$ in Humidified Nitrogen: Hydrated $\mathrm{H}_{2} \mathrm{SO}_{4}$, J. Phys. Chem. A., 104, 1715-1719, 2000.

Hinds, W. C.: Aerosol Technology: Properties, Behavior, and Measurement of Airborne Particles, John Wiley \& Sons, NJ, 1982

Hopke, P. K.: Contemporary threats and air pollution, Atmos. Environ., 43, 87-93, 2009.

Jeong, C.-H. and Evans, G. J.: Inter-Comparison of a Fast Mobility Particle Sizer and a Scanning Mobility Particle Sizer Incorporating an Ultrafine Water-Based Condensation Particle Counter, Aerosol Sci. Technol., 43, 364-373, 2009.

Jeong, C.-H. , Evans, G. J., Hopke, P. K., Chalupa, D., and Utell, M.: Influence of Atmospheric Dispersion and New Particle Formation Events on Ambient Particle Number Concentration in Rochester, United States, and Toronto, Canada, J. Air Waste
Manage. Assoc., 56, 431-443, 2006.

Jeong, C.-H., Hopke, P. K., Chalupa, D., and Utell, M.: Characteristics of Nucleation and Growth Events of Ultrafine Particles Measured in Rochester, NY, Environ. Sci. Technol., 38, 1933 1940, 2004.

Jung, J., Adams, P. J., and Pandis, S. N.: Simulating the size distribution and chemical composition of ultrafine particles during nucleation events, Atmos. Environ., 40, 2248-2259, 2006.

Kulmala, M., Laakso, L., Lehtinen, K. E. J., Riipinen, I., Dal Maso, M., Anttila, T., Kerminen, V.-M., Hñrrak, U., Vana, M., and Tammet, H.: Initial steps of aerosol growth, Atmos. Chem. Phys., 4, 2553-2560, doi:10.5194/acp-4-2553-2004, 2004a.

Kulmala, M., Petäjä, T., Mnkknen, P., Koponen, I. K., Dal Maso, M., Aalto, P. P., Lehtinen, K. E. J., and Kerminen, V.-M.: On the growth of nucleation mode particles: source rates of condensable vapor in polluted and clean environments, Atmos. Chem. Phys., 5, 409-416, doi:10.5194/acp-5-409-2005, 2005.

Kulmala, M., Vehkamaki, H., Petaja, T., Dal Maso, M., Lauri, A., Kerminen, V.-M., Birmili, W., and McMurry, P. H.: Formation and growth rates of ultrafine atmospheric particles: a review of observations, J. Aerosol Sci., 35, 143-176, 2004b.

Lehtinen, K. E. J., Korhonen, H., Dal Maso, M., and Kulmala, M.: On the concept of condensation sink diameter, Boreal Environ. Res., 8, 405-411, 2003.

Leskinen, A. P., Kulmala, M., and Lehtinen, K. E. J.: Growth of nucleation mode particles: Source rates of condensable vapour in a smog chamber, Atmos. Environ., 42, 7405-7411, 2008.

McMurry, P. H., Litchy, M., Huang, P.-F., Cai, X., Turpin, B. J., Dick, W. D., and Hanson, A.: Elemental composition and morphology of individual particles separated by size and hygroscopicity with the TDMA, Atmos. Environ., 30, 101-108, 1996.

McMurry, P. H.: A review of atmospheric aerosol measurements, Atmos. Environ., 34, 1959-1999, 2000.

Paul, M. W., Aron, V., Paul, E. W., Markku, K., Kari, E. J. L., and Timo, V.: Mass and Thermal Accommodation during GasLiquid Condensation of Water, Phys. Rev. Lett., 93, 075701, doi:10.1103/PhysRevLett.93.075701, 2004.

Pirjola, L., Kulmala, M., Wilck, M., Bischoff, A., Stratmann, F., and Otto, E.: Formation of Sulphuric Acid Aerosols and Cloud Condensation Nuclei: An Expression for Significant Nucleation and Model Comprarison, J. Aerosol Sci., 30, 1079-1094, 1999.

Qian, S., Sakurai, H., and McMurry, P. H.: Characteristics of regional nucleation events in urban East St. Louis, Atmos. Environ., 41, 4119-4127, 2007.

Reineking, A. and Porstendörfer, J.: Measurements of particle loss functions in a differential mobility analyzer (TSI, Model 3071) for different flow rates, Aerosol Sci. Technol., 5, 483-486, 1986.

Rodrigue, J., Ranjan, M., Hopke, P. K., and Dhaniyala, S.: Performance Comparison of Scanning Electrical Mobility Spectrometers, Aerosol Sci. Technol., 41, 360-368, 2007.

Schwab, J. J., Felton, H. D., and Demerian, K. L.: Aerosol Chemical Composition in New York State From Integrated Filter Samples: Urban/rural And Seasonal Contrasts, J. Geophys. Res., 109, D16S05, doi:10.1029/2003JD004078, 2004.

Schwab, J. J., Felton, H. D., Rattigan, O. V., and Demerian, K. L.: New York State Urban and Rural Measurements of Continuous PM2.5 Mass by FDMS, TEOM, and BAM, J. Air Waste Manage. Assoc., 56, 372-383, 2006.

Stanier, C.O ., Khlystov, A. Y., and Pandis, S. N.: Nucleation Events 
During the Pittsburgh Air Quality Study: Description and Relation to Key Meteorological, Gas Phase, and Aerosol Parameters, Aerosol Sci. Technol., 38, 253-264, 2004.

Su, W.-C., Wu, J., Marijnissen, J. C. M., and Cheng, Y. S.: Deposition of Man-Made Fibers in a Human Nasal Airway, Aerosol Sci. Technol., 42, 173-181, 2008.

TSI, Inc.: Scanning Mobility Particle Sizer (SMPS) Spectrometer Diffusion Loss Correction, Application Note SMPS-001, Shoreview, MN, 2006.

Wang, J., Flagan, R. C., and Seinfeld, J. H.: Diffusional losses in particle sampling systems containing bends and elbows, J. Aerosol Sci., 33, 843-857, 2002.
Watson, J. G., Chow, J. C., Park, K., and Lowenthal, D. H.: Nanoparticle and Ultrafine Particle Events at the Fresno Supersite, J. Air Waste Manage. Assoc., 56, 417-430, 2006.

Willeke, K.: Temperature dependence of particle slip in a gaseous medium, J. Aerosol Sci., 7, 381-387, 1976.

Zhang, Q., Canagaratna, M., Jayne, J. T., Worsnop, D. R., and Jimenez, J.-L.: Time- and Size-resolved Chemical Composition of Submicron Particles in Pittsburgh: Implications for Aerosol Sources and Processes, J. Geophys. Res., 110, D07S09, doi:10.1029/2004JD004649, 2005.

Zhang, R., Suh, I., Zhao, J., Zhang, D., Fortner, E. C., Tie, X., Molina, L. T., and Molina, M. J.: Atmospheric New Particle Formation Enhanced by Organic Acids, Science, 304, 1487-1490, 2004. 